(C) 2017. This manuscript version is made available under the CC-BY-NC-ND 4.0 license

http://creativecommons.org/licenses/by-nc-nd/4.0/

1

2

3

4

5

6

7

8 9 industrial application

\section{Abstract \\ Abstract}

\title{
Net thermoelectric power generation improvement through heat
}

\author{
P. Aranguren ${ }^{1,2 *}$, \\ D. Astrain ${ }^{1,2}$, A. Rodríguez ${ }^{1,2}$, A. Martínez ${ }^{1,2}$ \\ ${ }^{1}$ Mechanical, Energy and Materials Engineering Department Public University of \\ Navarre, 31006 Pamplona, Spain \\ ${ }^{2}$ Smart Cities Institute, Pamplona, Spain \\ *e-mail:patricia.arangureng@unavarra.es
}

Keywords: thermoelectric optimization; computational model; heat dissipators;

Thermoelectric generation contributes to obtain a more sustainable energetic system giving its potential to harvest waste heat and convert it into electric power. In the present study a computational optimal net generation of 108.05 MWh/year was produced out of the flue gases of a real tile furnace located in Spain (the equivalent to supply the energy to 31 Spanish dwellings). This maximum generation has been obtained through the optimization of the hot and cold heat exchangers, the number of thermoelectric modules (TEMs) installed and the mass flows of the refrigerants, including the temperature loss of the flue gases and the influence of the heat power to dissipate over the heat dissipators. The results are conclusive, the installation of more TEMs does not always imply higher thermoelectric generation, so the occupancy ratio $(\delta)$ has to be optimized. The optimal generation has been achieved covering the $42 \%$ of the surface of the chimney of the tile furnace with TEMs and using heat pipes on the cold side, which present smaller thermal resistances than the finned dissipators for similar consumptions of their fans. Moreover, the high influence of the consumption of the auxiliary equipment shows the importance of considering it to obtain realistic usable electric energy from real applications. 


\begin{tabular}{|c|c|c|}
\hline$\delta$ & Occupancy ratio & \\
\hline$\rho$ & Density & $\mathrm{Kg} / \mathrm{m}^{3}$ \\
\hline$\sigma$ & Thomson coefficient & $\mathrm{V} / \mathrm{K}$ \\
\hline$\alpha$ & Seebeck coefficient & $\mathrm{V} / \mathrm{K}$ \\
\hline$k$ & Thermal conductivity & $\mathrm{W} / \mathrm{mK}$ \\
\hline$c_{p}$ & Specific heat at constant pressure & $\mathrm{J} / \mathrm{kgK}$ \\
\hline$A_{T E M}$ & Area of a TEM & $\mathrm{m}^{2}$ \\
\hline$A_{b}$ & Area of the heat exchanger base & $\mathrm{m}^{2}$ \\
\hline$b_{R_{T E M}}$ & Systematic standard uncertainty & \\
\hline$\overline{E_{t}}$ & Electromotive force & $\mathrm{V}$ \\
\hline$I$ & Current supplied to the heat plates & A \\
\hline$M_{T E M}$ & Number of TEMs & \\
\hline$M_{\text {sample }}$ & Number of samples for each configuration & \\
\hline$\dot{m}_{a i}$ & Mass flow of the air & $\mathrm{kg} / \mathrm{s}$ \\
\hline$\dot{m}_{g a s}$ & Mass flow of the flue gases & $\mathrm{kg} / \mathrm{s}$ \\
\hline$n_{b l o}$ & Number of blocks of the pipe & \\
\hline$\dot{Q}_{C}$ & Heat power to dissipate & $\mathrm{W}$ \\
\hline$\dot{Q}^{i}$ & Heat power extracted from the flue gases in block "i" & $\mathrm{W}$ \\
\hline $\bar{q}$ & Volumetric heat generation & $\mathrm{W} / \mathrm{m}^{3}$ \\
\hline$R^{T E M}$ & Thermal resistance per thermoelectric module & $\mathrm{K} / \mathrm{W}$ \\
\hline$R_{C D}^{i}$ & Thermal resistance of the cold side heat dissipators of block "i" & $\mathrm{K} / \mathrm{W}$ \\
\hline$R_{\text {cont }}^{i}$ & Contact thermal resistance of block "i” & K/W \\
\hline$R_{H D}^{i}$ & Thermal resistance of the hot side heat dissipators of block "i" & $\mathrm{K} / \mathrm{W}$ \\
\hline
\end{tabular}




\begin{tabular}{|c|c|c|}
\hline$R_{p e r}^{i}$ & $\begin{array}{l}\text { Thermal resistance of the heat losses through the free surface } \\
\text { of block "i" }\end{array}$ & $\mathrm{K} / \mathrm{W}$ \\
\hline$R_{\text {tor }}^{i}$ & $\begin{array}{l}\text { Thermal resistance of the heat losses through the bolts of block } \\
\text { "i" }\end{array}$ & $\mathrm{K} / \mathrm{W}$ \\
\hline$S_{\bar{R}^{T E M}}$ & Random standard uncertainty of the mean & \\
\hline$T_{C}^{i}$ & Temperature of the cold sink in block " $i$ " & $\mathrm{K}$ \\
\hline$T_{C}^{T E M i}$ & Temperature of cold side of the TEMs in block "i" & K \\
\hline$T_{e}^{i}$ & Entry temperature of block "i" & K \\
\hline$T_{H}^{i}$ & Temperature of the heat source in block "i" & $\mathrm{K}$ \\
\hline$T_{H}^{T E M i}$ & Temperature of hot side of the TEMs in block "i" & $\mathrm{K}$ \\
\hline$T_{m}^{i}$ & Mean temperature of block "i” & $\mathrm{K}$ \\
\hline$T_{m}^{H X}$ & Mean temperature of the heat exchanger where heat is applied & $\mathrm{K}$ \\
\hline$T_{S}^{i}$ & Exit temperature of block "i”" & $\mathrm{K}$ \\
\hline$U_{R^{T E M}}$ & Expanded uncertainty & \\
\hline$v_{\text {gas }}$ & Velocity of the flue gases & $\mathrm{m} / \mathrm{s}$ \\
\hline V & Voltage supplied to the heat plates & $\mathrm{V}$ \\
\hline$\dot{W}_{\text {aux }}$ & Consumption of the auxiliary equipment & $\mathrm{W}$ \\
\hline$\dot{W}_{T E M}$ & Thermoelectric generation & $\mathrm{W}$ \\
\hline$\dot{W}_{\text {net }}$ & Net generation & $\mathrm{W}$ \\
\hline
\end{tabular}

\section{Introduction}

29 In the last decades, the increasing concern about global warming and pollution has

30 enhanced the study of new environmentally friendly power producing technologies. 
31 The thermoelectric generators (TEGs), solid-state thermal engines where the working

32 fluid is the charge carriers flow, have emerged as a promising alternative to producing

33 clean energy. This novel technology is able to convert any temperature grade heat into

34 electricity [1] and due to its solid-state operation, thermoelectricity presents advantages

35 such as reliability, scalability, durability, low noise operation, reduced size and lack of

36 maintenance given absence of moving parts [2]. Furthermore, its ability to recover any

37 kind of waste heat into electricity turns thermoelectricity into a promising option to help

38 to mitigate the global warming issue. The waste heat can be defined as a byproduct heat

39 that is not exploited afterwards. Nowadays, a large amount of the produced energy is

40 dissipated as waste heat. In the US just the $38 \%$ of the gross energy is used for its final

41 purpose [3]. It has been estimated that twice the heating energy demand in the USA could

42 be supplied with waste heat [4].

43 Nevertheless, TEGs present a major drawback, their efficiency is typically around 5-10

$44 \%$ [5]. Numerous investigations are trying to increase the efficiency of the generators

45 through the improvement of the thermoelectric materials [6,7] and/or the optimization of

46 the heat transfer within the TEG. The reduction of the thermal resistances of the heat

47 exchangers included into the TEGs increases the thermoelectric generation [8-11]. The optimization of the heat dissipation systems can be done modifying their geometry, such as increasing the number, height or spacing of the fins of a finned dissipator [12,13], or

50 including novel heat exchangers which present better thermal resistances, such as heat

51 pipes $[14,15]$. Nevertheless, the increase in the power generation does not necessarily

52 mean an improvement in the net generation (the usable energy obtained from any

53 application) due to the increase of the consumption of the auxiliary equipment $[16,17]$.

54 Computational models simulate the behavior of thermoelectric generators in real 55 scenarios, however in order to be as accurate as possible, they need to include the 
minimum number of simplifications possible. Each thermoelectric effect, each

57 component of the TEG (heat exchangers, ceramic plates, junctions...), properties dependent on temperature and transient resolution need to be considered [18-21]. Furthermore, new parameters as the temperature drop of the flue gases while they cross

60 the TEG, the consumption of the auxiliary equipment and the occupancy ratio (the ratio

61 between the area covered by TEMs and the base area of the heat exchanger, see equation

62 (1)), are vital to take into account into the computational modeling to optimize the generation. The occupancy ratio is a very influential parameter which defines the optimal thermoelectric generation [22-24]. A higher occupancy ratio is determined by more thermoelectric modules (TEMs) installed and thus more units which produce electric power; however the electric production of each unit decreases due to the worsening of the thermal resistance per TEM of the heat exchangers [15]. Meanwhile, the consumption of the auxiliary equipment defines the net generation (the thermoelectric generation minus the consumption of the auxiliary equipment) the real parameter to optimize [17].

$$
\delta=\frac{M_{T E M} A_{T E M}}{A_{b}}
$$

Lately research focus on the recovery of waste heat in many applications, such as an oil heater [12], a marine incinerator [25], a wood stove [21], an iron steel industry [26] and vehicles in order to improve their efficiency $[10,27,28]$, the most common applications. In the present study a general computational model able to compute the net thermoelectric generation obtained from the recovery of waste flue gases, which includes all the determinant parameters (including the occupancy ratio, the temperature

77 loss of the flue gases and the consumption of the auxiliary equipment) is presented. Moreover, two different kinds of heat exchangers are experimentally studied to obtain 
80 dissipate $\left(\dot{Q}_{C}\right)$ and the mass flow of the air $\left(\dot{m}_{a i}\right)$, in order to include them into the

81 model and optimize the thermoelectric generation of a real industrial application.

\section{Methodology and computational model}

83 The developed computational model simulates the electric generation of any TEG.

84 Moreover, this model has been specially designed to get the electrical power obtained

85 from the harvesting of waste flue gases. The model includes novel parameters such as the occupancy ratio, the mass flow of the refrigerants and the temperature loss of the flue gases. The temperature decrease of the flue gases is computed through the discretization of the flowing pipe into a number of blocks where the thermoelectric phenomena is solved. The temperature of the heat source of each block is obtained as the mean temperature between the entry and exit temperatures of the block $\left(T_{H}^{i}=T_{m}^{i}=\frac{1}{2}\left(T_{e}^{i}+\right.\right.$ $T_{S}^{i}$ ), as it can be seen in Figure 1. Within each block, the TEG is divided into 16 nodes that represent the whole device, including the heat source and heat sink and each element present in the TEG, such as the heat exchangers located on both sides of the TEMs (the hot and cold heat exchangers) and the TEMs (junctions, ceramics and thermoelectric material), as Figure 1 presents. Node 1 and 16 represent the heat source and heat sink respectively, nodes 2 and 15 are the hot and cold heat exchangers and the TEMs are represented in nodes 3 to 14 , where nodes 3 and 14 are the ceramic plates and 4-13 represent the thermoelectric material. It has been supposed that the entire heat that the flue gases loss reaches the hot side heat exchanger (as it is incorporated in the interior of the conducting pipe), as Figure 1 shows. The heat that arrives to the hot side heat exchanger can follow three paths. It can cross the screws that are in charge of assuring a proper assembly $\left(R_{\text {tor }}^{i}\right)$, it can be dissipated to the ambient through the free surfaces of the pipe $\left(R_{p e r}^{i}\right)$ or it can cross the TEMs, the heat flux that defines the electrical generation. 


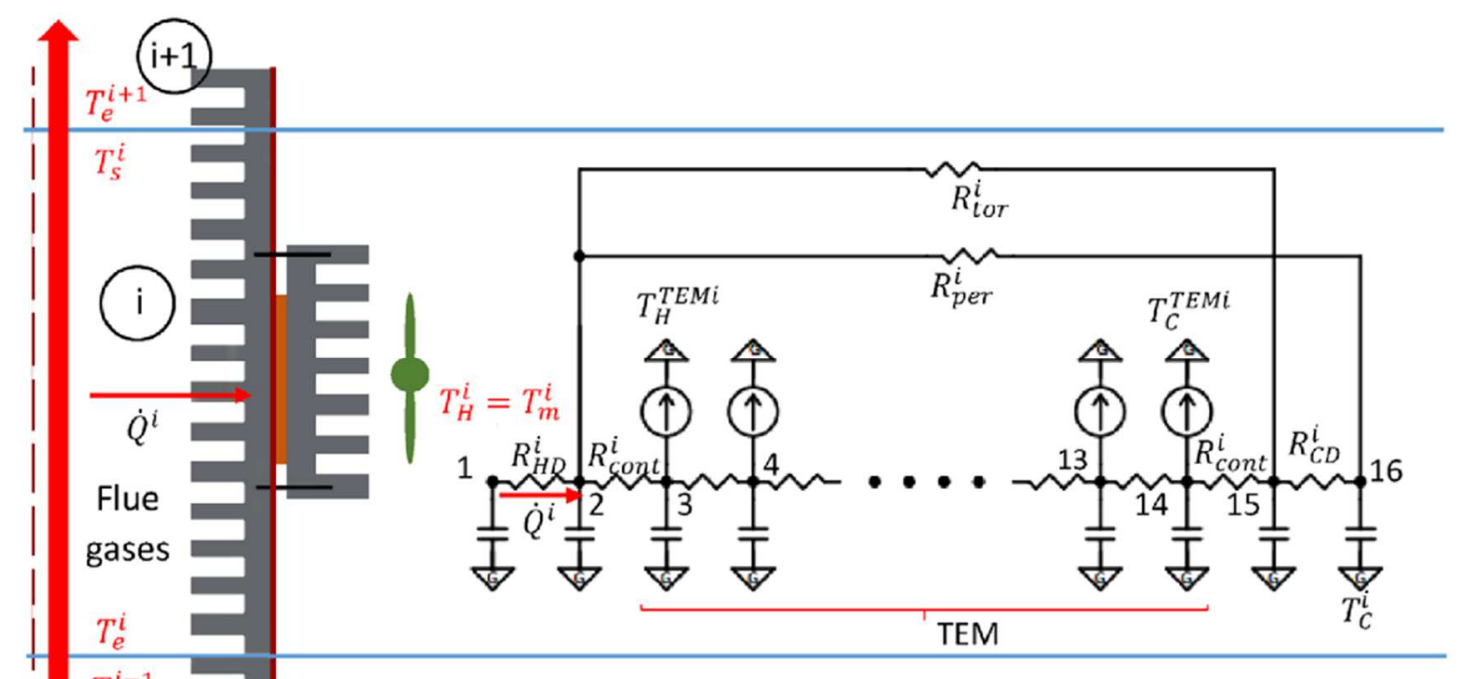

\begin{tabular}{|c|l|c|l|}
\hline Node & Description & Node & Description \\
\hline $\mathbf{1}$ & Heat source & $\mathbf{1 4}$ & Cold side of the TEM \\
\hline $\mathbf{2}$ & Hot side heat dissipator & $\mathbf{1 5}$ & Cold side heat dissipator \\
\hline $\mathbf{3}$ & Hot side of the TEM & $\mathbf{1 6}$ & Heat sink \\
\hline $\mathbf{4 - 1 3}$ & Thermoelectric material & & \\
\hline
\end{tabular}

108 The computational model is based on a previous model that has been already published

109 and validated $[29,30]$. It includes each thermoelectric phenomena that takes part in the

110 TEMs (equations (2)-(5)), it has dependent properties with temperature, solves the

111 transient behavior and includes each element of the thermoelectric generator. The

112 resolution is done solving the general expression of heat conduction within a solid with

113 internal heat generation (equation (6)) using the implicit finite difference method, under

114 the assumption of unidirectional heat transfer.

$$
\begin{gathered}
\alpha_{\mathrm{AB}}=\frac{d E_{t}}{d T}=\alpha_{A}-\alpha_{B} \\
\dot{\mathrm{Q}}_{\text {Peltier }}= \pm \pi_{\mathrm{AB}} I= \pm I T\left(\alpha_{A}-\alpha_{B}\right) \\
\dot{Q}_{\text {Thomson }}=-\sigma \vec{I}(\overrightarrow{\Delta T})
\end{gathered}
$$




$$
\begin{gathered}
\dot{Q}_{\text {Joule }}=R_{0} I^{2} \\
\rho c_{p} \frac{\delta T}{\delta t}=k\left(\frac{\delta^{2} T}{\delta x_{2}}+\frac{\delta^{2} T}{\delta y_{2}}+\frac{\delta^{2} T}{\delta z_{2}}\right)+\bar{q}
\end{gathered}
$$

116 The number of blocks in which the pipe is going to be divided and the occupancy ratio as

117 well as the geometry of the application are included into the modelling. The resolution

118 process starts with the supposition of the mean temperature of the flue gases of the first

119 block. The finite difference method solves the system through the thermal resistances and

120 the heat capacities (including the thermoelectric phenomena). To properly characterize

121 the thermal resistances of the heat exchangers, novel parameters are included, as the

122 occupancy ratio $(\delta)$, the heat power to dissipate $\left(\dot{Q}_{C}\right)$, and the mass flow of the air $\left(\dot{m}_{a i}\right)$.

123 While the occupancy ratio is selected by the user and the mass flow of the air can be

124 calculated from the consumption of the auxiliary equipment, the heat power to dissipate

125 is an outlet variable of the system which depends on the whole device, so it is unknown

126 in a first instance and needs to be supposed. The finite difference method obtains this heat

127 power closing the most interior iteration loop, as it can be seen in Figure 2. Once the heat

128 to dissipate is obtained, the mean temperature of the block is calculated and afterwards

129 compared to the supposed one to state if it is necessary to keep on iterating or not. To

130 obtain the mean temperature, the exit temperature is calculated through the heat extracted

131 from the flue gases (equation (7)), an output variable obtained from the resolution of the

132 thermoelectric phenomena. Once the mean temperature has converged, the block is

133 solved and the resolution can continue to the next block, supposing the mean temperature

134 of the new block which in a first instance equals the entry temperature of the block (the

135 exit temperature of the previous one).

$$
T_{s}^{i}=T_{e}^{i}-\frac{\dot{Q}^{i}}{\dot{m}_{g a s} c_{p}}
$$




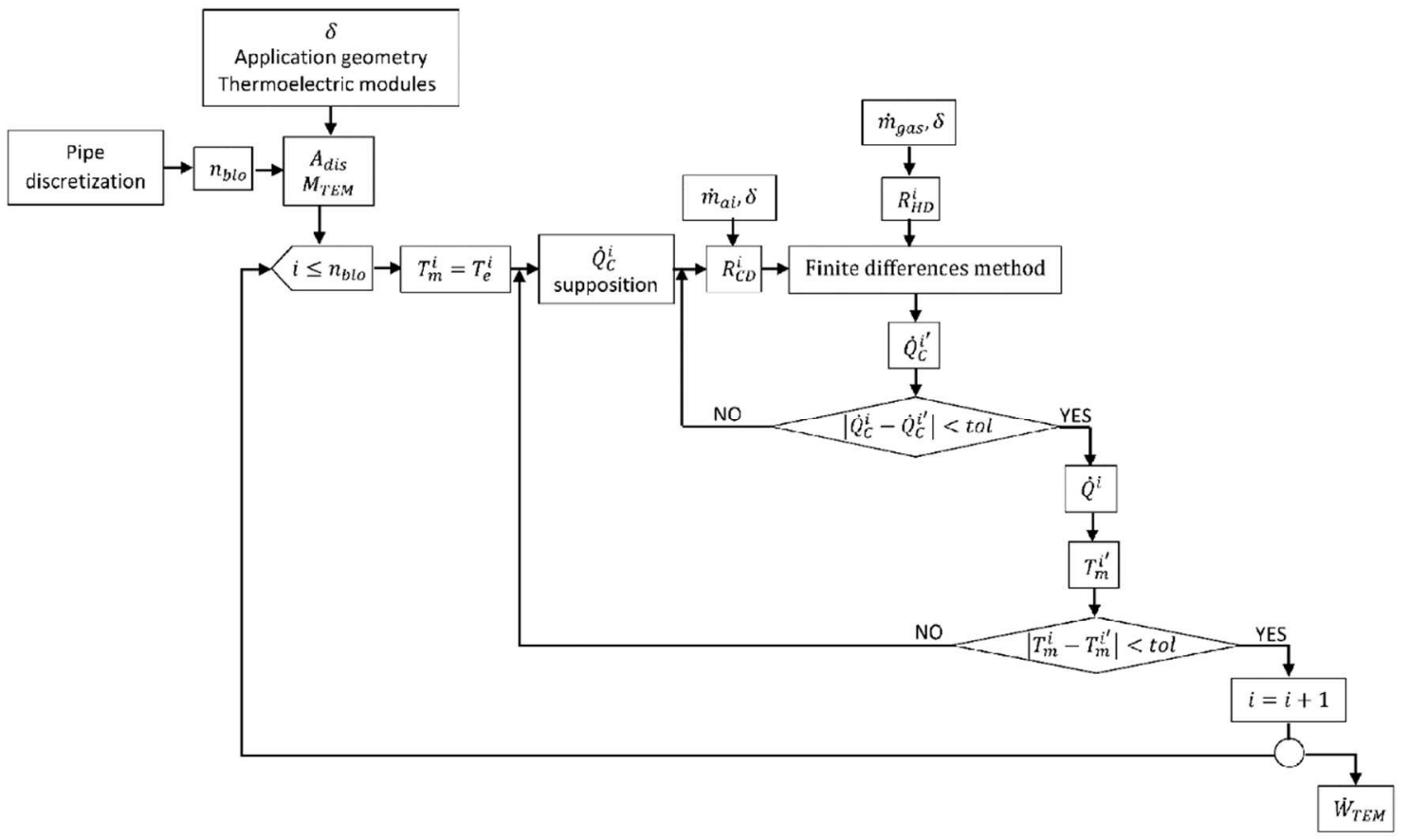

139 Figure 2 presents the methodology used in the computational model to obtain the total

140 thermoelectric generation, which is calculated adding the thermoelectric generation of

141 each block of the pipe. Nevertheless, the output to optimize in any application is the net

142 generation, the thermoelectric generation minus the consumption of the auxiliary

143 equipment $\left(\dot{W}_{n e t}=\dot{W}_{T E M}-\dot{W}_{a u x}\right)$, a variable that is easily computed with the

144 knowledge of the power supplied to the auxiliary equipment, which determines the mass

145 flow of the refrigerants.

146 The thermal characterization of the heat exchangers included in the TEG as a function of

147 the occupancy ratio, the air mass flows and the heat power to dissipate needs to be

148 included into the computational model in order to optimize the thermoelectric generation. 
152 The inclusion of the heat exchange devices into the computational modeling is essential.

153 The temperatures of both sides of the TEMs (which determine the thermoelectric 154 generation) highly depend on the heat exchangers, the heat source and sink and the 155 operation of the thermoelectric generator [31]. To optimize the thermoelectric generation 156 two different heat exchangers have been experimented, a finned dissipator and a heat 157 pipe, varying different variables that influence the thermoelectric generation. The 158 parameters that thermally characterize the heat exchangers are the occupancy ratio $(\delta)$, 159 the ratio of base area of the heat dissipator covered by TEMs (see equation (1)), the heat 160 power to dissipate $\left(\dot{Q}_{C}\right)$ and the mass flow of forced air that circulates over the fins of 161 both devices $\left(\dot{m}_{a i}\right)$.

162 The experimental setups of both heat dissipators are similar; a metal plate assures the 163 proper assembly of the system, ensuring good contact between the modules and the heat 164 dissipators. The heat plates define the occupancy ratio experimented $(\delta=0.073 ; \delta=0.146$; $165 \delta=0.293 ; \delta=0.439$ and $\delta=0.625)$ while the heat power to dissipate by the heat exchangers 166 is modified through the electric power supplied to them $(100 ; 150 ; 200 ; 300 ; 400$ and 500 167 W). The mass flow of the air is adjusted varying the electrical power supplied to the fans 168 that force the air through the fins of both devices.

169 The thermal resistance per TEM is calculated through equation (8) where $T_{m}^{H X}$ represents 170 the mean temperature of the heat exchanger where heat flux exists, $T_{a m b}$ is the ambient 171 temperature, $M_{T E M}$ is the number of TEMs experimented and $\dot{Q}_{C}$ is obtained as electrical 172 power supplied to the heat plates $\left(\dot{Q}_{C}=I V\right)$. The temperature probes have an accuracy of $173 \pm 0.5^{\circ} \mathrm{C}$ and a resolution of $0.1^{\circ} \mathrm{C}$, the electrical power supplied to the modules is obtained 174 multiplying the voltage and current measured, which have accuracies of $\pm 0.2 \mathrm{~V}$ and \pm 0.02 
175 A respectively and resolutions of $0.1 \mathrm{~V}$ and $0.01 \mathrm{~A}$ respectively. Table 1 presents the 176 accuracies and resolutions of the measurement probes used.

\begin{tabular}{|c|c|c|}
\hline Sensor & Resolution & Accuracy \\
\hline Temperature $\left({ }^{\mathbf{0}} \mathbf{C}\right)$ & 0.1 & \pm 0.5 \\
\hline Voltmeter $(\mathbf{V})$ & 0.1 & \pm 0.2 \\
\hline Ammeter $(\mathbf{A})$ & 0.01 & \pm 0.02 \\
\hline
\end{tabular}

Table 1. Resolution and accuracy of the measurement probes used

178

179 The expanded uncertainty of the experimental thermal resistance per thermoelectric

180 module is calculated as equation (9) presents [32] where $b_{R^{T E M}}$ is the standard systematic uncertainty (equation (10)), $S_{\bar{R}^{T E M}}$ is the mean random standard uncertainty (equation

182 (11)), and the factor 2 represents a confidence interval of the $95 \%$. To reduce the 183 uncertainty of the thermal resistance, three replicas were made for each configuration, 184 obtaining $M_{\text {sample }}=3$.

$$
\begin{gathered}
R^{T E M}=\frac{T_{m}^{H X}-T_{a m b}}{\frac{\dot{Q}_{C}}{M_{T E M}}} \\
U_{R^{T E M}}=2\left(b_{R^{T E M}}^{2}+s_{R^{T E M}}^{2}\right)^{\frac{1}{2}} \\
b_{R^{T E M}}^{2}=\left(\frac{\partial R^{T E M}}{\partial T_{m}}\right)^{2} b_{T_{m}}^{2}+\left(\frac{\partial R^{T E M}}{\partial T_{\text {amb }}}\right)^{2} b_{T_{a m b}}^{2}+\left(\frac{\partial R^{T E M}}{\partial V_{T E M}}\right)^{2} b_{V_{T E M}}^{2}+\left(\frac{\partial R^{T E M}}{\partial I_{T E M}}\right)^{2} b_{I_{T E M}}^{2} \\
S_{\bar{R}_{T E M}}^{2}=\frac{1}{M_{\text {sample }}\left(M_{\text {sample }}-1\right)} \sum_{k=1}^{M_{\text {sample }}}\left(R_{k}^{T E M}-\overline{R^{T E M}}\right)^{2} \\
\frac{1}{R^{T E M}}=\frac{1}{M_{\text {sample }}} \sum_{k=1}^{M_{\text {sample }}} R_{k}^{T E M}
\end{gathered}
$$

\section{a. Finned dissipator}

187 Finned dissipators are the simplest heat dissipators. Nevertheless, new heat dissipation

188 devices are being introduced into thermoelectricity in order to increase thermoelectric

189 generation [8,9]. Into this research, a finned dissipator and a heat pipe are studied in order 190 to optimize the generation. 
191 The studied finned dissipator can be found in Figure 3 a). It has a base thickness of 14.5

$192 \mathrm{~mm}$, a dimension of $230 \times 190 \mathrm{~mm}^{2}$ and its fins have a height, thickness and spacing of

$19339.5,1.5$ and $3.3 \mathrm{~mm}$ respectively. A wind tunnel provided with two fans JAMICON

194 JF1225S2H is collocated on the finned dissipator in order to make air circulate over its

195 fins, as it can be seen in Figure 3 a).

196 Figure 4 a) presents the influence of the heat power to dissipate over the thermal resistance

197 per TEM of the finned dissipator. The variation of the temperature of the air that the

198 modification of the heat power to dissipate produces, does not influence the thermal

199 resistance of the finned dissipator.

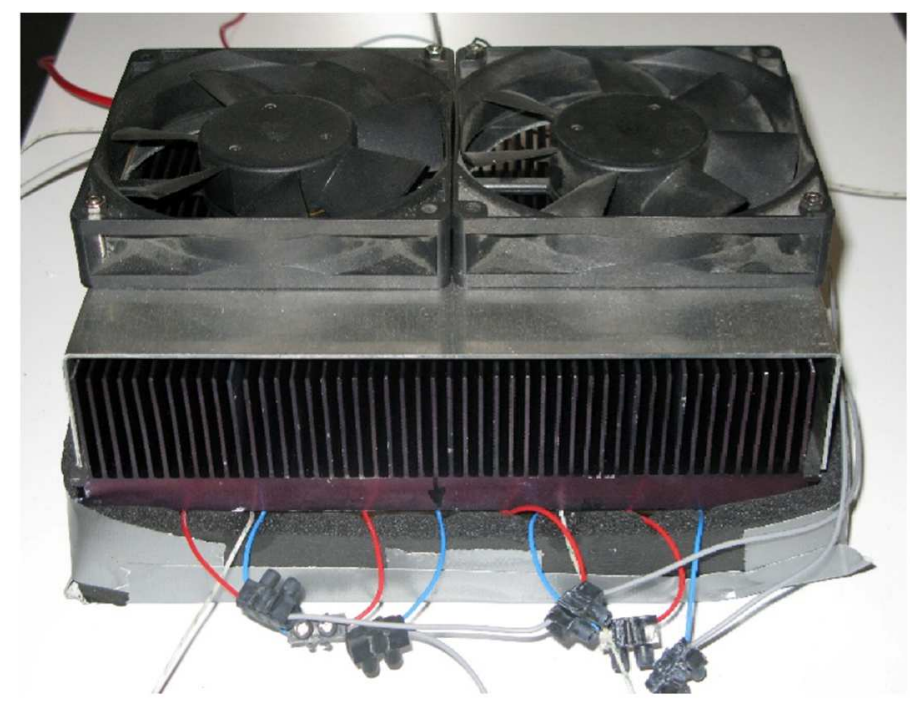

a)

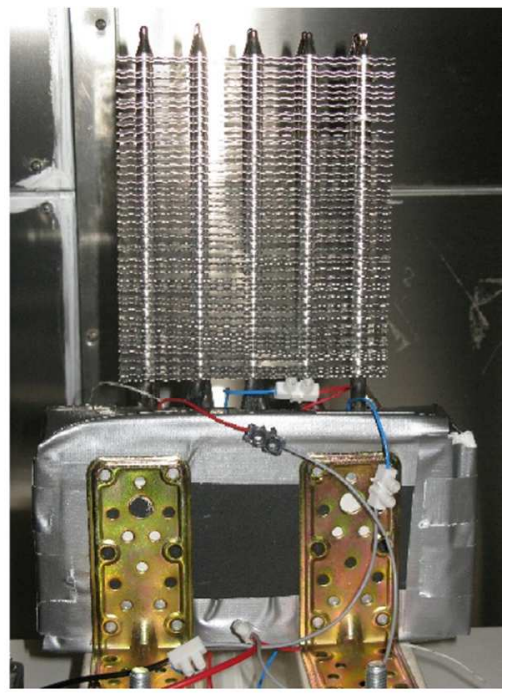

b)
200

Figure 3. Thermal resistance characterization. a) Finned dissipator, b) Heat pipe

The occupancy ratio represents the amount of the base surface of the heat exchanger that is covered by TEMs (equation (1)). A bigger occupancy ratio means more TEMs installed, consequently the thermal resistance of the finned dissipator per TEM gets bigger, as observed in Figure 4 b). As the number of TEMs grows the effective dissipative area of each one decreases, negatively influencing the thermal resistance per TEM. Figure $4 \mathrm{~b}$ ) presents the scarce influence that the air mass flow has on the thermal resistance per TEM 
209 when the occupancy ratio is small. In these cases, the thermal resistance does scarcely

210 change with the modification of the convection coefficients because the effective

211 dissipative area that each TEM presents is very big. When the area is small (big

212 occupancy ratios) the air mass flow strongly influences the thermal resistance.

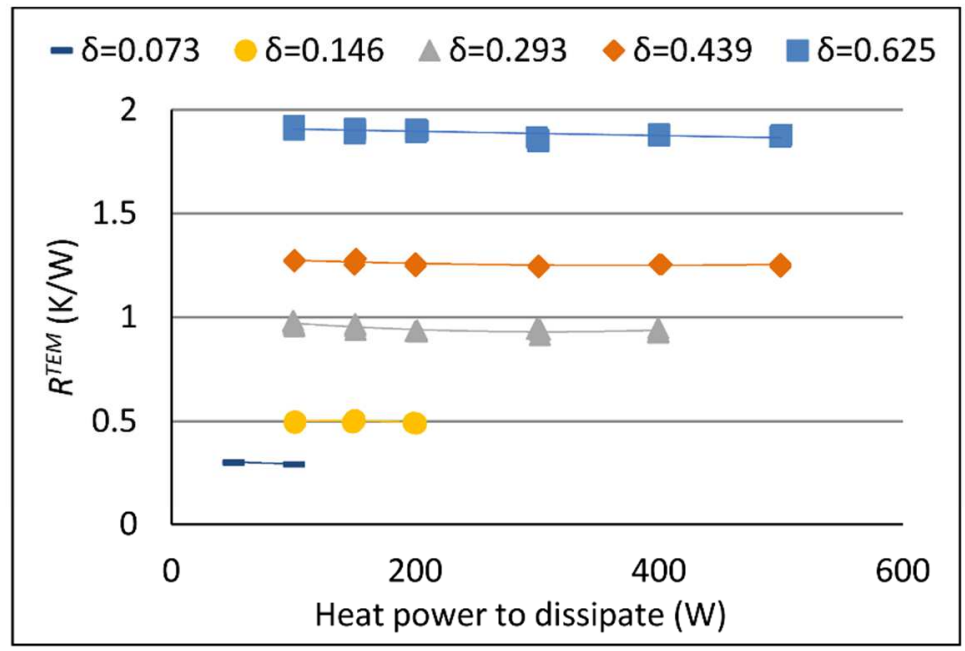

a)

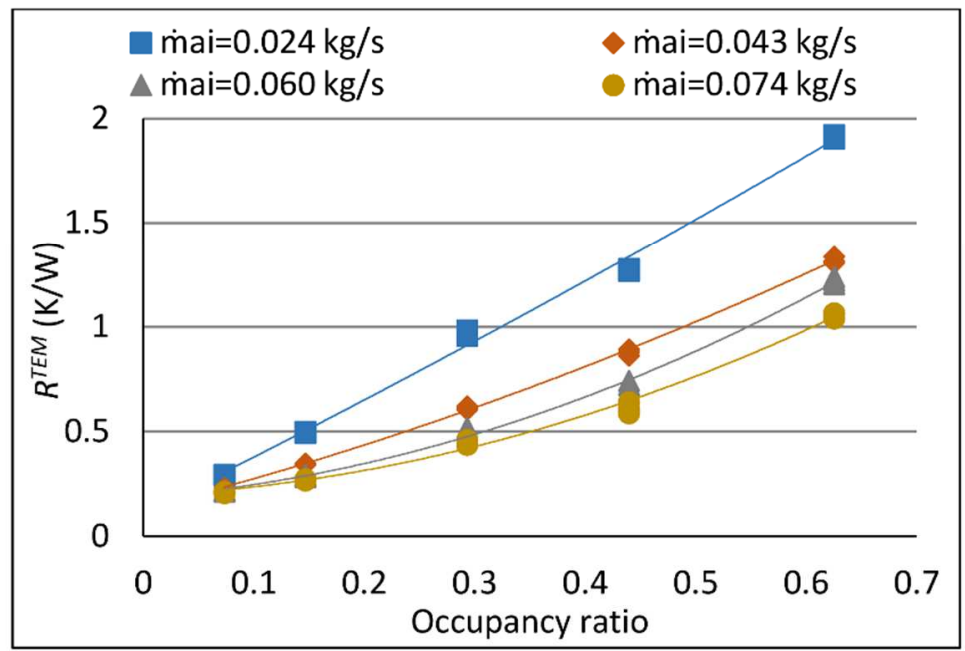

b)

214 Figure 4. Thermal resistance of the finned dissipator per TEM. a) Dependence with the

215 heat power to dissipate for an air mass flow of $\dot{m}_{a i}=0.024 \mathrm{~kg} / \mathrm{s}$, b) Dependence with the occupancy ratio 
218 The air mass flow that circulates over the fins was obtained as a function of the power

219 consumed by the fans. Figure 5 presents the consumption of the auxiliary equipment as a

220 function of the air mass flow for the finned dissipator and the heat pipe studied. As it can

221 be observed, both devices present similar consumptions for different air mass flows. A

222 bigger air mass flow causes a reduction in the thermal resistance of any heat dissipator,

223 however, this increase means an increment in the consumption of the auxiliary equipment,

224 which can negatively influence the thermoelectric generation as it can be seen in section

225 "Thermoelectric generation optimization".

226 The maximum expanded uncertainty of the measured thermal resistance per TEM of the

227 finned dissipator is expressed in equation (13)

$$
R^{T E M}=R^{T E M} \pm 10.80 \%
$$

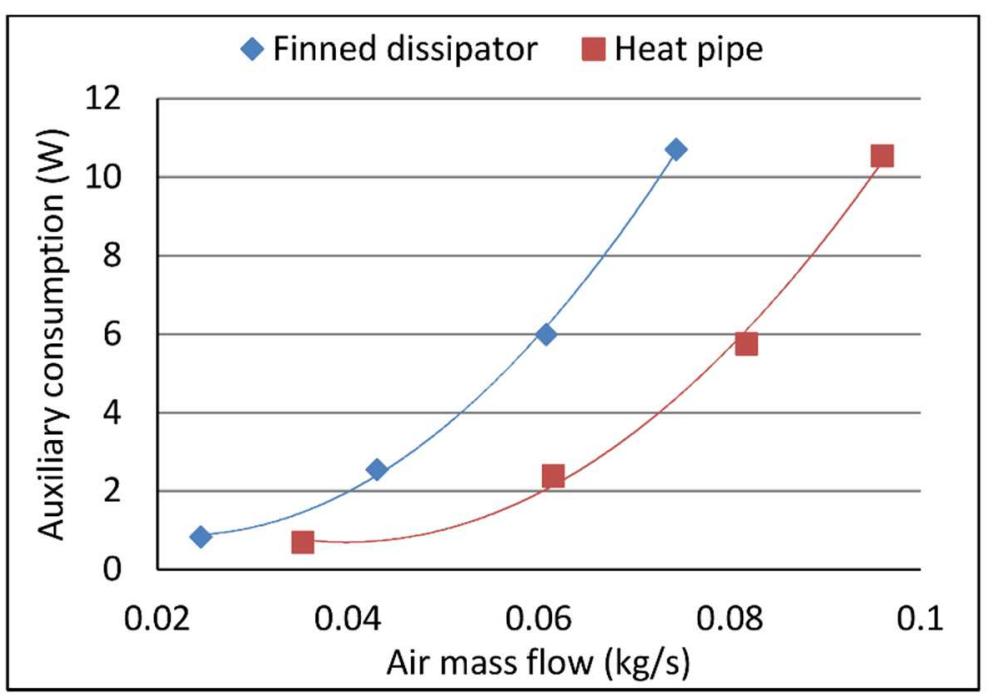

230 Figure 5. Auxiliary consumption of the fans as a function of the air mass flow 


\section{b. Heat pipe}

234 A heat pipe is composed by tree regions: the evaporator, the condenser and the adiabatic 235 region. The inner liquid evaporates, due to the heat gain, flows to the condenser where 236 the liquid condenses and returns to the evaporator thanks to the capillary system, which 237 could conduct the liquid to the evaporator against gravity.

238 The heat pipe experimented has 10 pipes spaced $7 \mathrm{~mm}$, with an exterior diameter of $8 \mathrm{~mm}$, 239 a length of $350 \mathrm{~mm}$. The working fluid is water. The TEMs are located on the heat transfer 240 interface, which presents a dimension of $90 \times 182.5 \mathrm{~mm}^{2}$. To facilitate the condensation

241 of the water, the end of the pipes are provided with fins, which are spaced $3 \mathrm{~mm}$ and 242 present an external dimension of $130 \times 55 \mathrm{~mm}^{2}$. Figure $3 \mathrm{~b}$ ) presents the detail of the 243 tubing and the fins that form the heat pipe. A wind tunnel provided with a fan is disposed 244 over the end of the pipes helping to improve the convective term and therefore reducing 245 the thermal resistance of the heat pipe.

246 Figure 6 a) presents the dependence of the thermal resistance per TEM of the heat pipe 247 with respect to the heat power to dissipate. The heat power to dissipate modifies the 248 temperatures of the system, while the boiling and condensation coefficients highly depend 249 on the temperature differences, defining the thermal resistance of the system. To assess 250 the influence of the occupancy ratio and the air mass flow, a heat power of $100 \mathrm{~W}$ has 251 been selected, as Figure 6 b) depicts. This figure presents the same tendency, the increase 252 of the occupancy ratio increments the thermal resistance per thermoelectric module. Once 253 more, high occupancy ratios experiment stronger influence with respect to the air mass 254 flow than the lower ones. The thermal resistance is influenced because each TEM presents small effective convective areas and any increase in the air mass flow, any improvement of the convective coefficient, provokes reductions in the resistance values. The same 
257 tendencies for the occupancy ratio and the mass flow of the air can be observed for the 258 different heat powers tested.

259

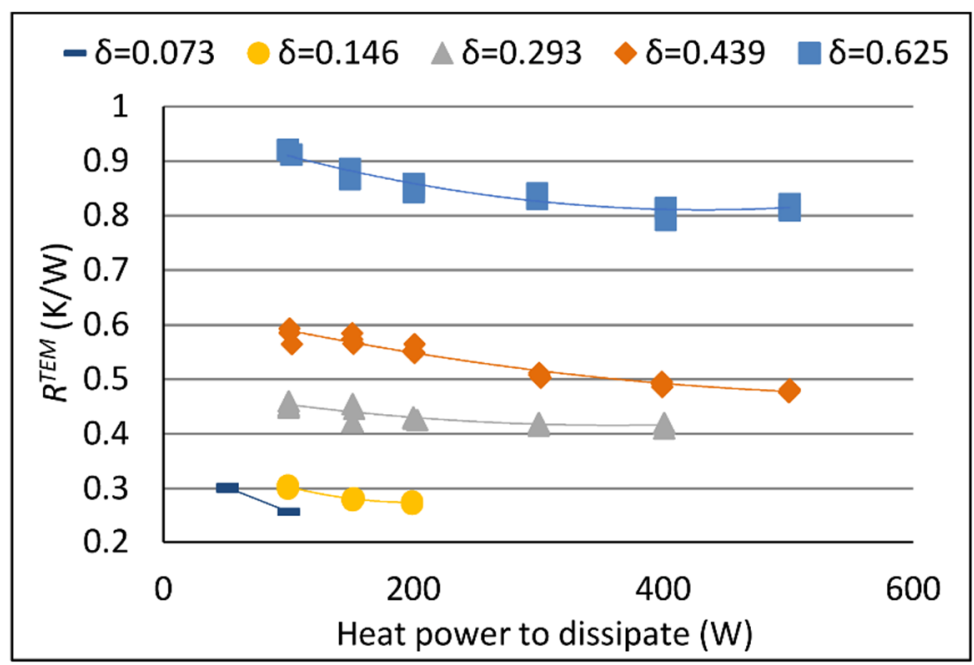

a)

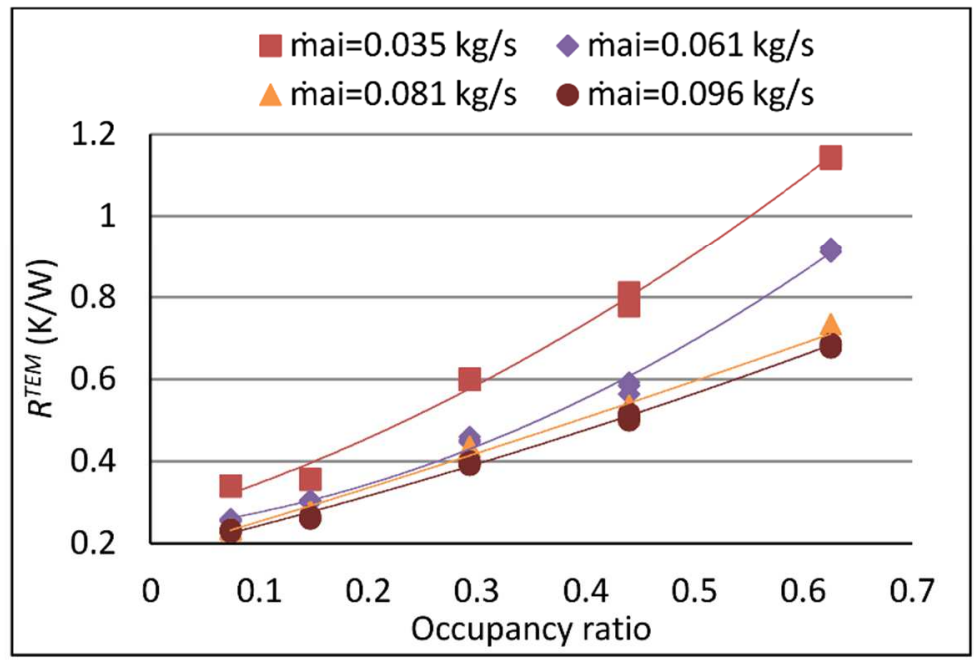

b)

Figure 6. Thermal resistance of the heat pipe per TEM. a) Dependence with the heat

262 power to dissipate for an air mass flow of $\dot{m}_{a i}=0.061 \mathrm{~kg} / \mathrm{s}$, b) Dependence with the occupancy ratio for a heat power to dissipate equal to $\dot{Q}_{C}=100 \mathrm{~W}$

265 The thermal resistance per TEM of the heat pipe is less influenced by the studied factors 266 than that of the finned dissipator. The resistance of the finned dissipator varies in the 
range of [0.21-1.92] $\mathrm{K} / \mathrm{W}$ while that of the heat pipe does it within the $[0.23-1.16] \mathrm{K} / \mathrm{W}$ range, for the same occupancy ratio, heat power to dissipate and consumption of the fans intervals.

270 The maximum expanded uncertainty of the measured thermal resistance per TEM of the

271 heat pipe is expressed in equation (14)

$$
R^{T E M}=R^{T E M} \pm 7.88 \%
$$

272

\section{Thermoelectric optimization applied to a real case}

\section{a. Real industrial application description}

The flue gases emitted to the ambient by the Spanish industry chosen have a mass flow of $5.49 \mathrm{~kg} / \mathrm{s}\left(18405 \mathrm{Nm}^{3} / \mathrm{h}\right)$ and a temperature of $187^{\circ} \mathrm{C}$. To obtain the maximum power generation, the general computational model presented in section "Methodology and computational model" is used where the experimental thermal resistances exposed in section "Thermal characterization of the heat exchangers" as a function of the occupancy ratio, the heat power to dissipate and the air mass flow are included. The chimney presents a diameter of $0.8 \mathrm{~m}\left(0.5 \mathrm{~m}^{2}\right.$ of transversal area) and a height of $12 \mathrm{~m}$. To maintain the same transversal area, but to accommodate the TEMs, the chimney has been transformed into a quadrangular section pipe with a length of $0.7 \mathrm{~m}$. The chimney presents a total surface area of $33.6 \mathrm{~m}^{2}$ where the TEMs can be located.

The computational model considers the cooling of the flue gases through the discretization of the chimney. Figure 7 presents the sensibility study conducted to select the number of blocks the chimney is divided. The figure represents the thermoelectric generation $\left(\dot{W}_{\text {TEM }}\right)$ and the computational time as a function of the number of blocks. It can be seen that the generation slightly varies when more than 5 blocks are simulated, while the difference from 1 to 5 simulated blocks is notorious. Nevertheless, the 
computational time needed to solve a particular case greatly increases with the increasing

292 number of blocks. Hence, in this case the chimney has been divided into 5 blocks to

293 obtain accurate results but without needing a substantial computational time.

294 Their thermal resistances as a function of the occupancy ratio and the velocity of the flue 295 gases were computationally obtained from a CFD program, ANSYS Fluent. Specifically 296 three finned dissipator were simulated, all of them with a base thickness of $4 \mathrm{~mm}$ and fins 297 of $1.5 \mathrm{~mm}$ thickness of and height of $50 \mathrm{~mm}$. They differ in their fin spacing, 14, 10 and $6 \mathrm{~mm}$, called 5014, 5010 and 5006 finned dissipator respectively.

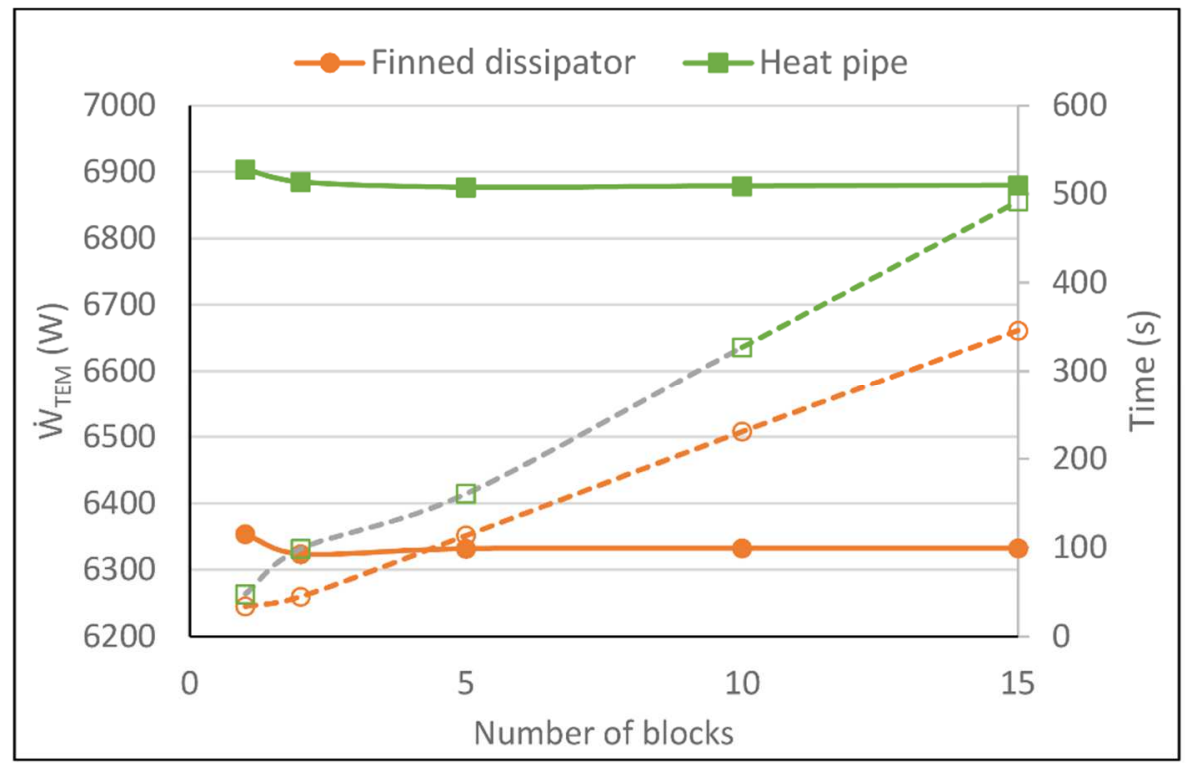

Figure 7. Sensibility study to get the number of block in which the chimney is divided

In the interior of the chimney, finned dissipators can be found to enhance the heat

304 Figure 8 presents the thermal resistance per thermoelectric module of the finned dissipator located in the interior of the chimney with a spacing of $6 \mathrm{~mm}$ as a function of the occupancy ratio and the velocity of the flue gases. The heat power to dissipate has not

307 been modified into the simulations because as it was concluded in the previous section, it

308 does not influence the thermal resistance per thermoelectric module of the finned 
309 dissipators. Equations (15)-(17) present the thermal resistance per thermoelectric module

310 of the finned dissipators located in the interior of the chimney as a function of the velocity

311 of the flue gases and the occupancy ratio that have been obtained through computational

312 simulation by the CFD software.

313

314 Figure 8. Thermal resistance per thermoelectric module of the 5006 finned dissipator

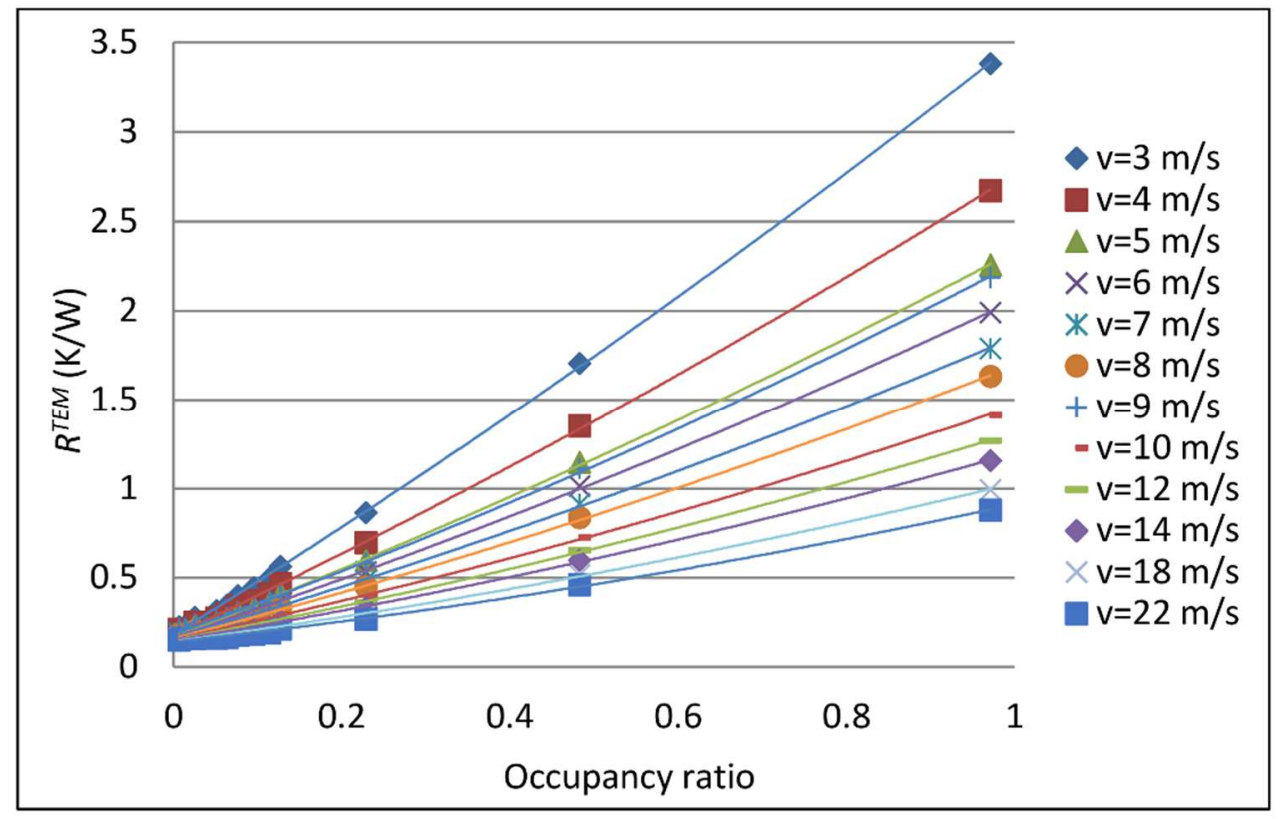

315 that is located in the interior of the chimney as a function of the occupancy ratio

316

317

$$
\begin{aligned}
& R_{5006}^{T E M}=0.046127-0.887591 * \delta-0.000251 * v_{\text {gas }}+0.385376 * 1 / \ln \left(v_{\text {gas }}\right) \\
&+ 0.304593 * \delta^{2}-0.281665 * 1 / \ln ^{2}\left(v_{\text {gas }}\right)+4.35262 \\
& * \delta / \ln \left(v_{\text {gas }}\right) \\
& R_{5010}^{T E M}=0.3523-0.857347 * \delta-0.016483 * v_{\text {gas }}+0.000350 * 1 / \ln \left(v_{\text {gas }}\right) \\
&+ 0.393804 * \delta^{2}-0.172064 * 1 / \ln ^{2}\left(v_{\text {gas }}\right)+5.44766 \\
& * \delta / \ln \left(v_{\text {gas }}\right) \\
& R_{5014}^{T E M}=-0.0130407-0.99456 * \delta-0.0026427 * v_{\text {gas }}+0.90492 * 1 / \ln \left(v_{\text {gas }}\right) \\
&+ 0.42743 * \delta^{2}-0.771231 * 1 / \ln ^{2}\left(v_{\text {gas }}\right)+7.15277 \\
& * \delta / \ln \left(v_{\text {gas }}\right)
\end{aligned}
$$

318 The TEMs used for the simulation are TG12-8-01L which are $40 \times 40 \mathrm{~mm}^{2}$ and specially

319 built to support temperatures up to $250^{\circ} \mathrm{C}$ [33] while the ambient temperature has been

320 selected equal to $17^{\circ} \mathrm{C}$, the mean temperature of the region where the furnace is located.

321 The computational model obtains the thermoelectric generation $\left(\dot{W}_{T E M}\right)$, however, the 
real parameter to optimize is the net generation (equation (18)). The consumption of the auxiliary equipment is calculated through the number of heat exchangers that cover the total surface of the chimney and the consumption of the fans that can be found in Figure 5 as a function of the air mass flow.

$$
\dot{W}_{\text {net }}=\dot{W}_{T E M}-\dot{W}_{\text {aux }}
$$

\section{b. Thermoelectric generation optimization}

328 Figure 9 presents the thermoelectric and net generation that occurs in the tile furnace 329 when 5014 finned dissipators are located in the interior of the chimney and finned

330 dissipators, as the ones previously studied, are placed on the outside. Figure 9 depicts

331 how the installation of more TEMs does not imply a higher thermoelectric generation. As

332 the occupancy ratio grows, the thermoelectric resistance of the heat exchangers per TEM

333 also increases, reducing the temperature difference between the sides of the TEMs and

334 thus producing less thermoelectric generation per unit. The maximum thermoelectric 335 generation occurs when the occupancy ratio is between 0.3 and 0.4 . It can also be seen

336 that higher air mass flows produce bigger thermoelectric generations, but not necessarily

337 higher net generations. In fact, the maximum net generation, the real parameter to 338 optimize, is obtained when the air mass flow is close to the smallest simulated value, 339 showing the importance of including the consumption of the auxiliary consumption into 340 the optimization. The flue gases loss stands between 60 and $70{ }^{\circ} \mathrm{C}$ because of the heat

341 extracted to produce electric power, as Figure 10 presents. This figure presents how 342 important is to account for the temperature reduction of the flue gases in order to obtain 343 accurate results of the thermoelectric generation. 


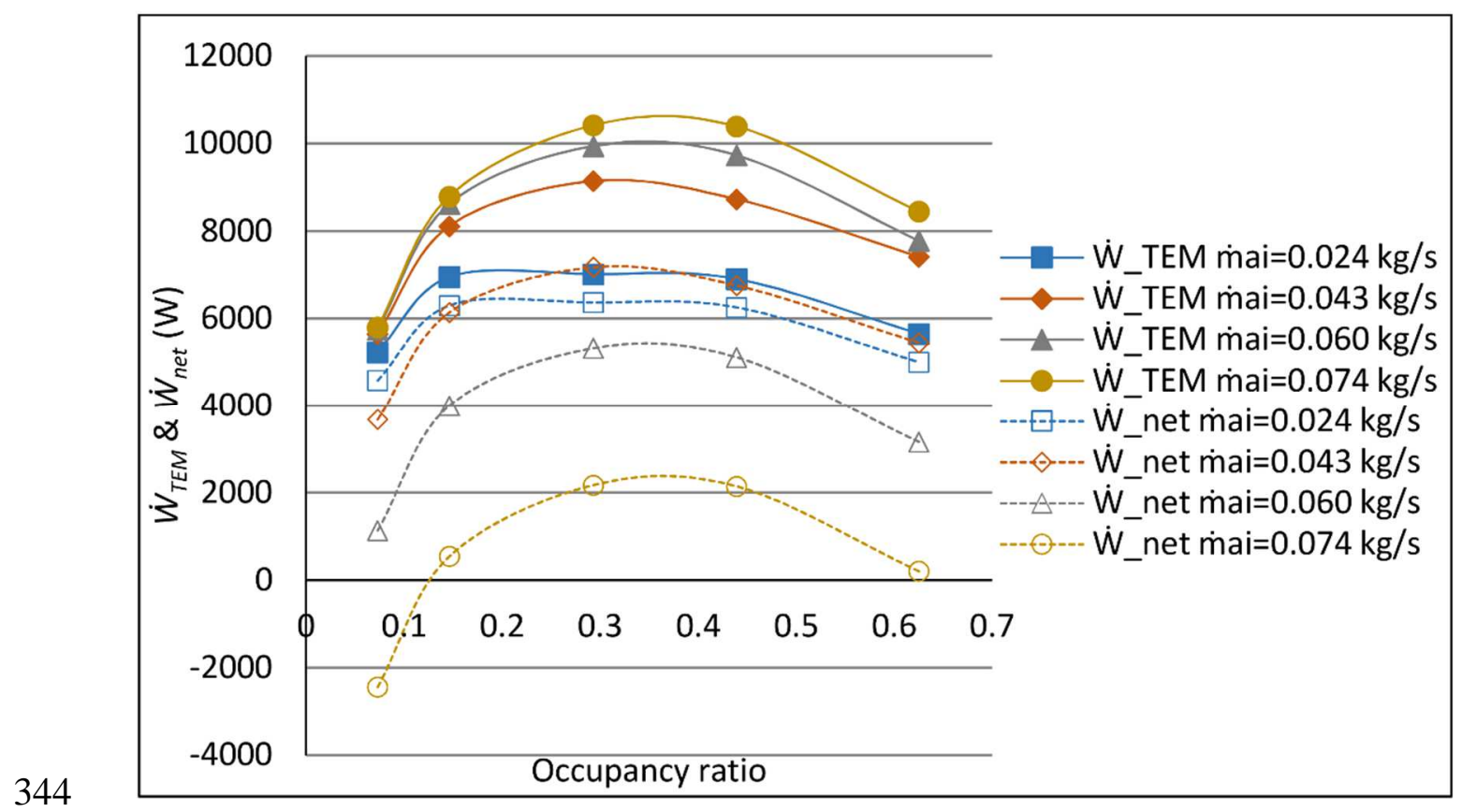

345 Figure 9. Thermoelectric and net generation of the flue gases as a function of the

346 occupancy ratio when finned dissipators are located on the cold side of the chimney and the 5014 dissipator is located inside.

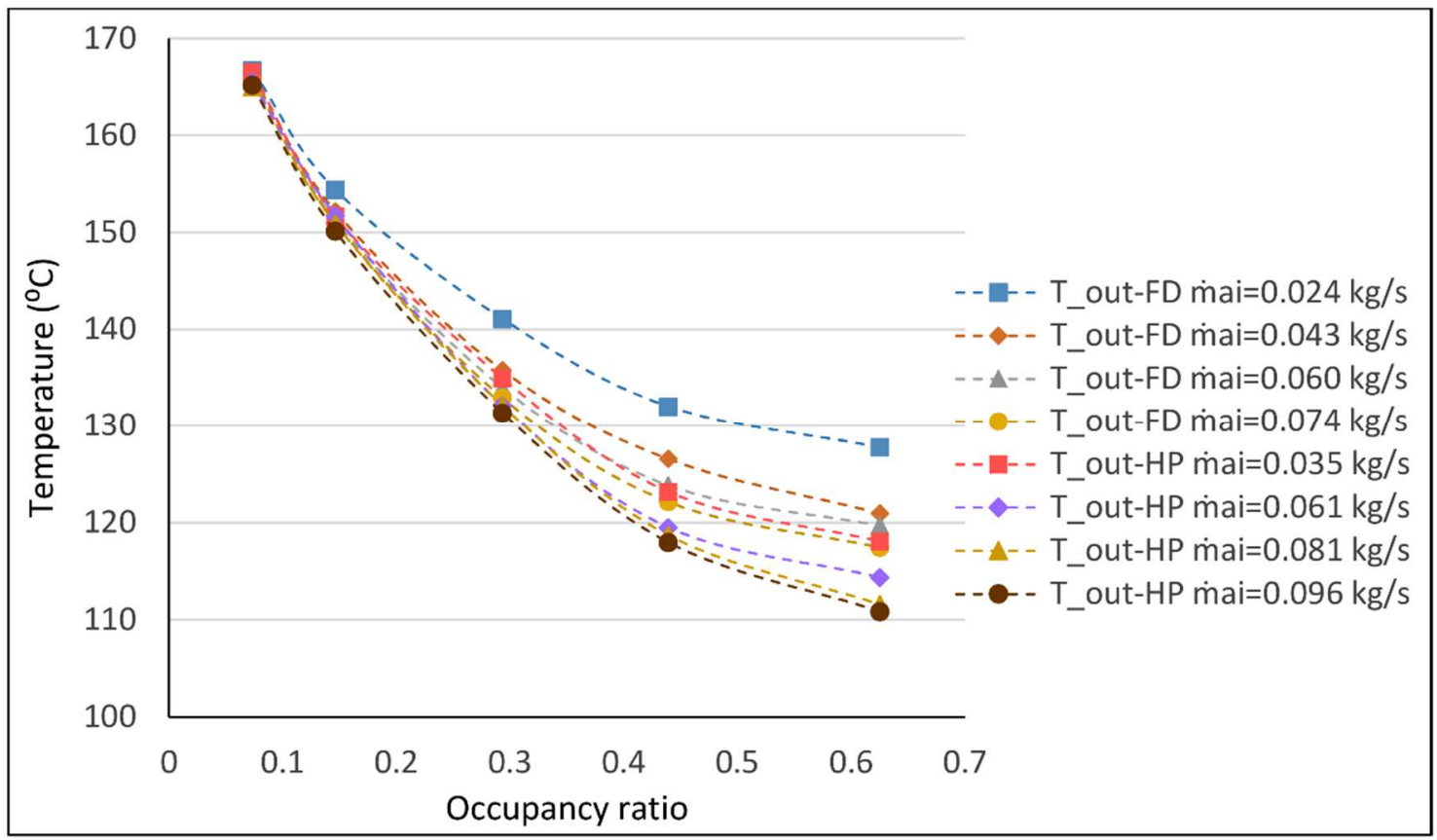

349 Figure 10. Output temperature of the flue gases as a function of the air mass flow when

350 heat pipes (HP) and finned dissipators (FD) are located on the cold side of the chimney and the 5014 dissipator is located inside. 
352 Figure 11 presents similar results but when heat pipes are simulated for the exterior

353 surface of the chimney. The negative influence of the increase of the air mass flow can

354 be found, specially for small occupancy ratios where the maximum net generation occurs

355 at the smallest mass flows. Higher occupancy ratios present optimum points for the net

356 generation at higher consumption of the auxiliary equipment because the small effective

357 areas per thermoelectric module require higher convective coefficients. Nevertheless,

358 these optimal points are close to the smallest air mass flow simulated. Negative net

359 generations can also be found for the smallest occupancy ratio and high air mass flows,

360 these scenarios are undesirable because the power supplied to the fans is higher than the

361 thermoelctric generation.

362

363

364

365

366

367 When heat pipes are simulated, the maximum net generation occurs for occupancy ratios

Figure 11. Thermoelectric and net generation of the flue gases as a function of the air mass flow when heat pipes are located on the cold side of the chimney and the 5014 dissipator is located inside. of 0.42 , when the $42 \%$ of the exterior surface of the chimeny is covered by TEMs. The

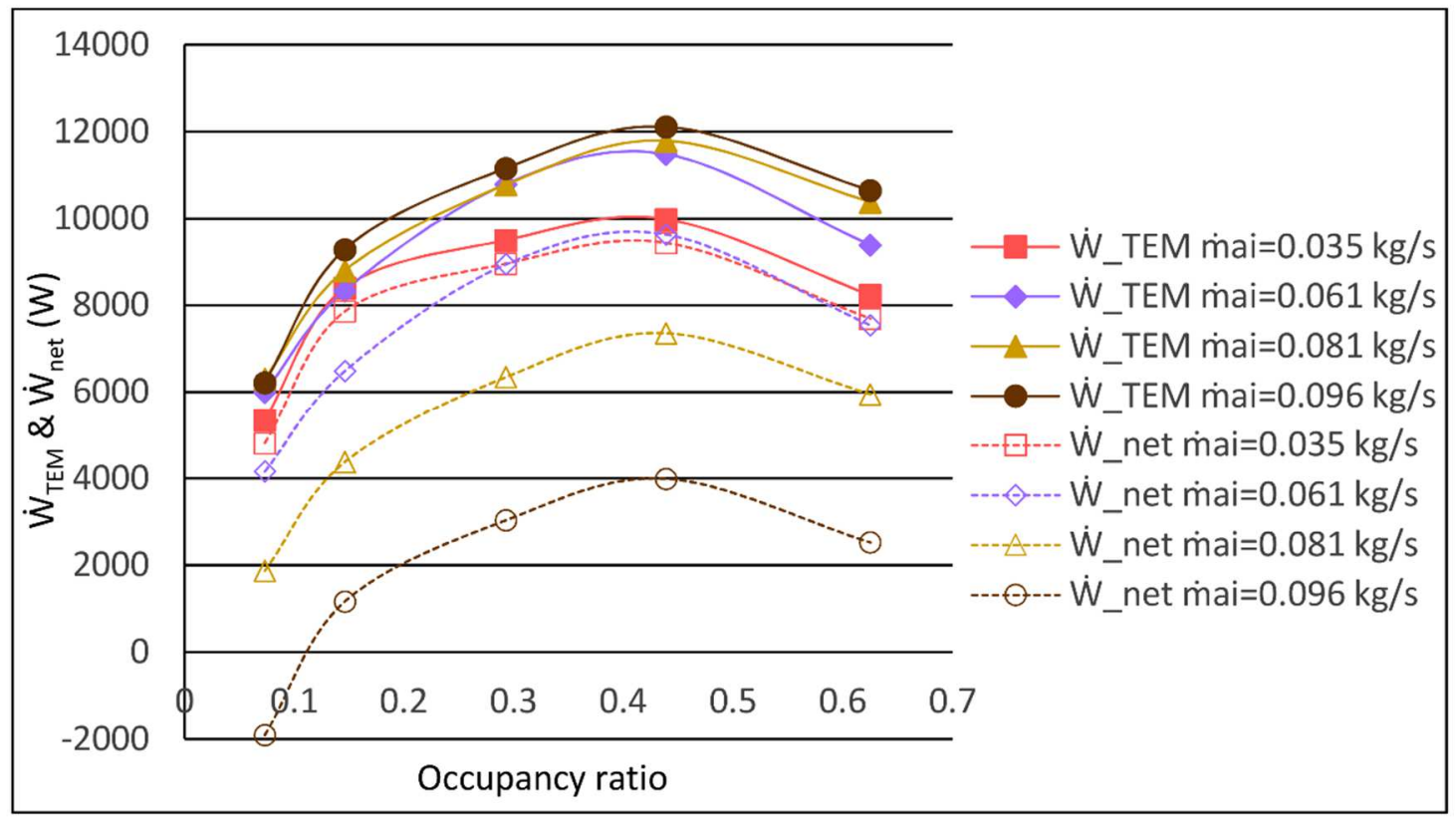


temperature output of the flue gases is slightly smaller than in the case of the finned

370 dissipators due to the higher heat power extracted from the smoke that is represented in

371 higher thermoelectric generations, as Figure 10 shows.

372 The reduction of the spacing between the fins of the heat dissipators that are located in

373 the interior of the chimney boost the net thermoelectric generation. The finned dissipators

374 obtain a $26 \%$ higher net thermoelectric generation if the fin spacing is decreased to $6 \mathrm{~mm}$

375 while the increase for the heat pipes equals the $29 \%$.

376 Figure 12 presents the optimal net generations for each occupancy ratio when heat pipes

377 and finned dissipators are simulated for dissimilar spacings of the interior finned

378 dissipators. It can be observed that the heat pipes outperform the finned dissipators, their

379 optimal net generation is a $42 \%$ higher than that of the finned dissipators. The

380 consumption of the fans on both heat dissipators are practically similar, as Figure 5

381 presents, so the higher net generation that the heat pipes present is due to the smaller

382 thermal resistance they present, as it is shown in Figure 9 and Figure 11. The occupancy

383 ratio that generates the maximum net energy is different for both heat dissipators. The

384 thermal resistance of the finned dissipators has a greater variation with the occupancy

385 ratio than that of the heat pipes, hence, the maximum generation occurs for smaller 386 occupancy ratios than in the case of the heat pipes.

387 The optimization of the thermal resistances of the cold and hot heat dissipators is 388 necessary, these reductions offer substantial increments in the thermoelectric generation, 389 as it has been demonstrated in the above lines. Figure 12 presents the maximum net 390 generation that occurs when the occupancy ratio is 0.42 (the $42 \%$ of the chimney surface 391 is covered by $8820 \mathrm{TEMs}$ ). A total of $12863 \mathrm{~W}, 108.05 \mathrm{MWh} /$ year taking into account 392 that the tile furnace works 8400 hours in a year, is produced out of waste heat. 


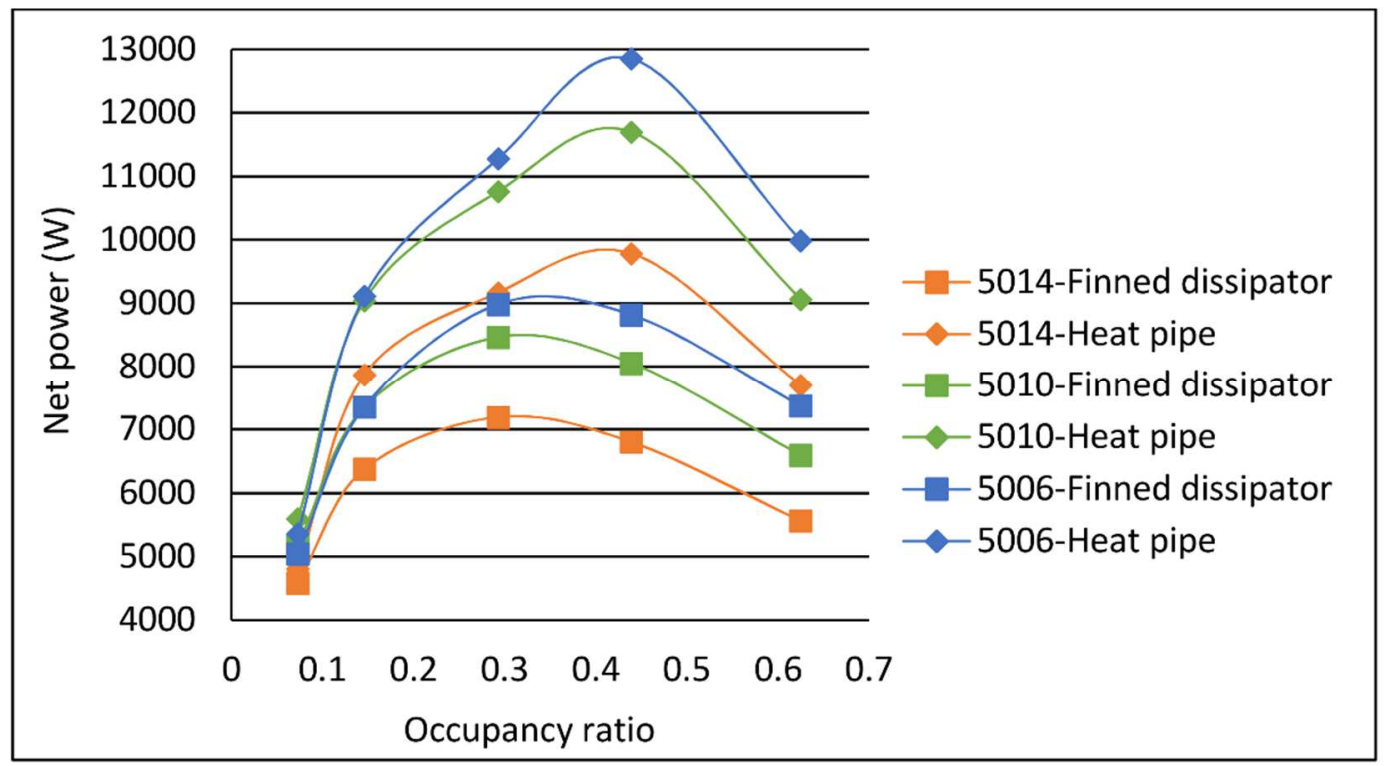

394 Figure 12. Optimal net generation when finned dissipators and heat pipes are simulated for different spacing of the finned dissipator of the interior of the chimney

397 Figure 12 shows the potential that thermoelectric generation has to harvest waste heat and to produce electricity out of it. Any TEGs located at the exhaust of any process contribute to increase their energetic efficiency, reducing the polluting gases emissions to the ambient and thus helping to achieve a sustainable energetic system.

401

\section{Conclusions}

403 The increased concern about the global warming and the rice in the pollution levels have

404 boost the research on new technologies able to palliate this effect. This study presents a 405 promising tecnology, the thermoelectricity, which is able to increase the efficiency of applications through the harvesting of waste heat to produce electric energy. The computational optimization conducted obtains up to 108.05 MWh/year from an Spanish

408 industry, the equivalent to energetically supply 31 Spanish dwellings.

409 A methodology able to optimize any thermoelectric generation is presented. A general 410 computational model has been developed. This model does not present any simplification 
411 to resolve the thermoelectric phenomena and includes each component of the

412 thermoelectric generator. Furthermore, novel factors such as the occupancy ratio, and the

413 temperature loss of the flue gases are included into the modeling, factors that highly

414 influence the thermoelectric and net generation.

415 The optimization of the thermoelectric net generation (the generated power minus the

416 consumption of the auxiliary equipment) has been conducted by virtue of the

417 computational model and the experimental thermal resistances obtained. The reduction

418 of the fin spacing of the finned dissipators located in the interior of the chimney produces

419 a power increase of the $29 \%$ while the use of heat pipes instead of finned dissipators on

420 the exterior surface produces a $42 \%$ higher net generation. Both improvements are due

421 to the reduction of the thermal resistances of the systems, without increasing the

422 consumption of the auxiliary equipment. The optimal generations happen for small occupancy ratios (the increase of the occupancy ratio worsens the thermal resistances per

TEM of the heat dissipation systems), showing that the increment of the number of installed TEMs does not always imply an increse in the generation while it does mean an increase in the initial investment.

\section{Acknowledgments}

428 The authors are indebted to the Spanish Ministry of Economy and Competitiveness for the economic support to this work, included in the DPI2014-53158-R research project.

\section{$431 \quad$ References}

432 [1] Lawrence Livermore National LaboratoryEnergy flow chart. Energy Use in 2013: 97.4 quads, 2014. http://flowcharts.llnl.gov/ n.d.

[2] Riffat SB, Ma X. Thermoelectrics: A review of present and potential applications. Appl Therm Eng 2003;23:913-35. doi:10.1016/S13594311(03)00012-7.

[3] Adams TM, Jeter SM, Qureshis ZH. An experimental investigation of singlephase forced convection in microchannels 1997;41:851-7.

[4] Rattner AS, Garimella S. Energy harvesting, reuse and upgrade to reduce primary 
energy usage in the USA. Energy 2011;36:6172-83.

doi:10.1016/j.energy.2011.07.047.

[5] Ming T, Wu Y, Peng C, Tao Y. Thermal analysis on a segmented thermoelectric generator. Energy 2015;80:388-99. doi:10.1016/j.energy.2014.11.080.

[6] Zhao LD, Lo SH, Zhang Y, Sun H, Tan G, Uher C, et al. Ultralow thermal conductivity and high thermoelectric figure of merit in SnSe crystals 2014;508:373-7. doi:10.1038/nature13184.

[7] Szczech JR, Higgins JM, Jin S. Enhancement of the thermoelectric properties in nanoscale and nanostructured materials. J Mater Chem A 2011;21:4037-55. doi:10.1039/c0jm02755c.

[8] Wang H, McCarty R, Salvador JR, Yamamoto A, König J. Determination of thermoelectric module efficiency: A survey. J Electron Mater 2014;43:2274-86. doi:10.1007/s11664-014-3044-2.

[9] Zhou S, Sammakia BG, White B, Borgesen P, Chen C. Multiscale modeling of Thermoelectric Generators for conversion performance enhancement. Int J Heat Mass Transf 2015;81:639-45. doi:10.1016/j.ijheatmasstransfer.2014.10.068.

[10] Su CQ, Wang WS, Liu X, Deng YD. Simulation and experimental study on thermal optimization of the heat exchanger for automotive exhaust-based thermoelectric generators. Case Stud Therm Eng 2014;4:85-91.

[11] Meng F, Chen L, Sun F. A numerical model and comparative investigation of a thermoelectric generator with multi-irreversibilities. Energy 2011;36:3513-22. doi:10.1016/j.energy.2011.03.057.

[12] Barma MC, Riaz M, Saidur R, Long BD. Estimation of thermoelectric power generation by recovering waste heat from Biomass fired thermal oil heater. Energy Convers Manag 2015;98:303-13. doi:10.1016/j.enconman.2015.03.103.

[13] Wang C-C, Hung C-I, Chen W-H. Design of heat sink for improving the performance of thermoelectric generator using two-stage optimization. Energy 2012;39:236-45. doi:http://dx.doi.org/10.1016/j.energy.2012.01.025.

[14] Brito FP, Martins J, Hançer E, Antunes N, Gonçalves LM. Thermoelectric Exhaust Heat Recovery with Heat Pipe-Based Thermal Control. J Electron Mater 2015;44:1984-97. doi:10.1007/s11664-015-3638-3.

[15] Chen J, Zuo L, Wu Y, Klein J. Modeling, experiments and optimization of an onpipe thermoelectric generator. Energy Convers Manag 2016;122:298-309. doi:10.1016/j.enconman.2016.05.087.

[16] Aranguren P, Astrain D, Rodríguez A, Martínez A. Experimental investigation of the applicability of a thermoelectric generator to recover waste heat from a combustion chamber. Appl Energy 2015;152:121-30. doi:10.1016/j.apenergy.2015.04.077.

[17] Aranguren P, Astrain D, Pérez MG. Computational and experimental study of a complete heat dissipation system using water as heat carrier placed on a thermoelectric generator. Energy 2014;74:346-58. doi:10.1016/j.energy.2014.06.094.

[18] Meng F, Chen L, Sun F. Effects of temperature dependence of thermoelectric properties on the power and efficiency of a multielement thermoelectric generator. Int J Energy Environ 2012;3:137-50.

[19] Nguyen NQ, Pochiraju K V. Behavior of thermoelectric generators exposed to transient heat sources. Appl Therm Eng 2013;51:1-9. doi:10.1016/j.applthermaleng.2012.08.050.

[20] Montecucco a., Buckle JR, Knox a. R. Solution to the 1-D unsteady heat conduction equation with internal Joule heat generation for thermoelectric 
devices. Appl Therm Eng 2012;35:177-84. doi:10.1016/j.applthermaleng.2011.10.026.

[21] Nuwayhid RY, Shihadeh A, Ghaddar N. Development and testing of a domestic woodstove thermoelectric generator with natural convection cooling. Energy Convers Manag 2005;46:1631-43. doi:10.1016/j.enconman.2004.07.006.

[22] Favarel C, Bédécarrats JP, Kousksou T, Champier D. Numerical optimization of the occupancy rate of thermoelectric generators to produce the highest electrical power. Energy 2014;68:104-16. doi:10.1016/j.energy.2014.02.030.

[23] Gomez M, Ohara B, Reid R, Lee H. Investigation of the effect of electrical current variance on thermoelectric energy harvesting. J Electron Mater 2014;43:1744-51. doi:10.1007/s11664-013-2854-y.

[24] Zemin D, Chen L, Yanlin G, Fengrui S. Performance Analysis for an Irreversible Combined Thermionic-Thermoelectric Generator With Finite Rate Heat Transfer. Environ Eng Manag J 2015;14:97-108.

[25] Kristiansen NR, Snyder GJ, Nielsen HK, Rosendahl L. Waste heat recovery from a marine waste incinerator using a thermoelectric generator. J Electron Mater 2012;41:1024-9. doi:10.1007/s11664-012-2009-6.

[26] Meng F, Chen L, Sun F, Yang B. Thermoelectric power generation driven by blast furnace slag flushing water. Energy 2014;66:965-72. doi:10.1016/j.energy.2014.02.018.

[27] Kempf N, Zhang Y. Design and optimization of automotive thermoelectric generators for maximum fuel efficiency improvement. Energy Convers Manag 2016;121:224-31. doi:10.1016/j.enconman.2016.05.035.

[28] Tao C, Chen G, Mu Y, Liu L, Zhai P. Simulation and Design of Vehicle Exhaust Power Generation Systems: The Interaction Between the Heat Exchanger and the Thermoelectric Modules. J Electron Mater 2014;44:1822-33. doi:10.1007/s11664-014-3568-5.

[29] Rodríguez A, Vián JG, Astrain D, Martínez A. Study of thermoelectric systems applied to electric power generation. Energy Convers Manag 2009;50:1236-43. doi:10.1016/j.enconman.2009.01.036.

[30] Astrain D, Vián JG, Martínez A, Rodríguez A. Study of the influence of heat exchangers' thermal resistances on a thermoelectric generation system. Energy 2010;35:602-10. doi:10.1016/j.energy.2009.10.031.

[31] Alata M, Al-Nimr MA, Naji M. Transient behavior of a thermoelectric device under the hyperbolic heat conduction model. Int J Thermophys 2003;24:1753-68. doi:10.1023/B:IJOT.0000004103.26293.0c.

[32] Coleman HW, Steele WG. Experimentation, Validation, and Uncertainty Analysis for Engineers, 3rd Edition -. Wiley; n.d.

[33] TG12-8-01L Power Generators | Generator Modules n.d. http://www.marlow.com/power-generators/standard-generators/tg12-8-011.html (accessed February 15, 2017). 